\title{
Immunohistochemical localization of the $\mathrm{NH}_{2}$-terminal and COOH-terminal fragments of dentin sialoprotein in mouse teeth
}

\author{
Guohua Yuan, \\ Key Laboratory for Oral Biomedicine of Ministry of Education, School and Hospital of \\ Stomatology, Wuhan University, Wuhan, Hubei, People's Republic of China 430079 \\ Guobin Yang, \\ Key Laboratory for Oral Biomedicine of Ministry of Education, School and Hospital of \\ Stomatology, Wuhan University, Wuhan, Hubei, People's Republic of China 430079 \\ Guangtai Song, \\ Key Laboratory for Oral Biomedicine of Ministry of Education, School and Hospital of \\ Stomatology, Wuhan University, Wuhan, Hubei, People's Republic of China 430079 \\ Zhi Chen, and \\ Key Laboratory for Oral Biomedicine of Ministry of Education, School and Hospital of \\ Stomatology, Wuhan University, Wuhan, Hubei, People's Republic of China 430079 \\ Shuo Chen \\ Department of Developmental Dentistry, The University of Texas Health Science Center at San \\ Antonio, San Antonio, TX 78229-3900, USA
}

Zhi Chen: zhichen@whu.edu.cn; Shuo Chen: chens0@uthscsa.edu

\section{Abstract}

Dentin sialoprotein (DSP) is a major non-collagenous protein in dentin. Mutation studies in human, along with gene knockout and transgenic experiments in mice, have confirmed the critical role of DSP for dentin formation. Our previous study reported that DSP is processed into fragments in mouse odontoblast-like cells. In order to gain insights into the function of DSP fragments, we further evaluated the expression pattern of DSP in the mouse odontoblast-like cells using immunohistochemistry and western blot assay with antibodies against the $\mathrm{NH}_{2}$-terminal and $\mathrm{COOH}$-terminal regions of DSP. Then, the distribution profiles of the DSP $\mathrm{NH}_{2}$-terminal and $\mathrm{COOH}$-terminal fragments and osteopontin (OPN) were investigated in mouse teeth at different ages by immunohistochemistry. In the odontoblast-like cells, multiple low molecular weight DSP fragments were detected, suggesting that part of the DSP protein was processed in the odontoblastlike cells. In mouse first lower molars, immunoreactions for anti-DSP-NH $\mathrm{N}_{2}$ antibody were intense in the predentin matrix but weak in mineralized dentin; in contrast, for anti-DSP-COOH antibody, strong immunoreactions were found in mineralized dentin, in particular dentinal tubules but weak in predentin. Therefore, DSP $\mathrm{NH}_{2}$-terminal and $\mathrm{COOH}$-terminal fragments from odontoblasts were secreted to different parts of teeth, suggesting that they may play distinct roles in dentinogenesis. Meanwhile, both DSP antibodies showed weak staining in reactionary dentin (RD), whereas osteopontin (OPN) was clearly positive in RD. Therefore, DSP may be less crucial for RD formation than OPN.

(C) Springer-Verlag 2012

Correspondence to: Zhi Chen, zhichen@whu . edu.cn; Shuo Chen, chens o@uthscsa . edu.

Guohua Yuan and Guobin Yang contributed equally.

Electronic supplementary material The online version of this article (doi:10.1007/s00441-012-1418-4) contains supplementary material, which is available to authorized users. 


\section{Keywords}

Dentin; Dentin sialoprotein; Immunohistochemistry; Predentin; Reactionary dentin

\section{Introduction}

Dentin is one of the major mineralized tissues of tooth and originates from odontoblasts. Dentin is classified as primary, secondary and tertiary dentin according to the developmental stages and conditions under which it is formed. The dentin produced during tooth formation is termed primary dentin. Once formation of the tooth is complete, dentinogenesis continues at a much slower rate, resulting in secondary dentin. Tertiary dentin, formed in response to external stimuli or injury, is classified into two types: reparative dentin and reactionary dentin (RD). If the intensity of the injury is of a magnitude resulting in original odontoblast death, reparative dentin is formed by a new generation of odontoblast-like cells differentiated from pulp cells. If the original odontoblasts are viable after injury, RD is formed by the surviving odontoblasts (Goldberg and Smith 2004; Moses et al. 2006).

The dentin extracellular matrix (ECM) contains a number of non-collagenous proteins (NCPs), which are believed to be responsible for initiating and modulating the mineralization of collagen fibers when predentin is converted to dentin (Qin et al. 2004). Dentin sialoprotein (DSP) and dentin phosphoprotein (DPP) are two major NCPs in dentin ECM. Cloning and sequencing of the cDNA indicate that DSP and DPP are encoded by a single gene, dentin sialophosphoprotein (DSPP). DSP and DPP originate from the $\mathrm{NH}_{2}-$ terminal and $\mathrm{COOH}$-terminal regions of the DSPP amino acid sequence, respectively. The COOH-terminus for mouse DSP ends at Gly ${ }^{451}$ (MacDougall et al. 1997).

In earlier studies, DSP was considered to be tooth-specific because it was found specifically expressed in odontoblasts, predentin, dentin and dental pulp and transiently expressed in pre-ameloblasts (Begue-Kirn et al. 1998; Bleicher et al. 1999; Bronckers et al. 1993; Butler et al. 1992; Chen et al. 2005; D’Souza et al. 1992; Ritchie et al. 1994, 1995, 1996). However, recent studies have indicated that DSP is more extensively distributed than originally thought. DSP expression has been detected in the inner ear (Xiao et al. 2001), bone (Qin et al. 2002, 2003a), periodontium (Baba et al. 2004a), breast and lung cancer (Fisher et al. 2004), salivary glands (Ogbureke and Fisher 2004; Prasad et al. 2011), kidney and brain (Yuan et al. 2009a, b; Prasad et al. 2011), liver, cartilage (Sun et al. 2010a; Prasad et al. 2011) and hair follicles (Tang et al. 2011) but its expression levels in these tissues are much lower than in dentin. The importance of DSP for dentin formation has been demonstrated by mutation studies in humans and by gene ablation and transgenic experiments in mice. Heterogeneous mutations of the DSP domain in humans are associated with dentinogenesis imperfecta type II (DGI-II) and dentin dysplasia type II (DD-II) (Kim and Simmer 2007; Rajpar et al. 2002; Xiao et al. 2001). DSPP null mice show phenotypes similar to the manifestations of human dentinogenesis imperfecta type III (Sreenath et al. 2003). Expression of a DSP transgene in the DSPP null background results in a partial rescue of the DSPP null phenotype with the restored predentin width, an absence of irregular unmineralized areas in dentin and less frequent pulp exposure (Suzuki et al. 2009).

Although DSP and DPP are abundant in the ECM of dentin, only a small quantity of fulllength DSPP was found in extracts from the pulp/odontoblast and dentin (Sun et al. 2010b), suggesting that the majority of the full-length DSPP is immediately cleaved after translation. Our previous study demonstrated that DSP, the $\mathrm{NH}_{2}$-terminal fragment of DSPP, was further cleaved into different small fragments in odontoblast-like cells (Chen et al. 2008). DSP shares overall characteristics with other SIBLING (Small Integrin-Binding Ligand N- 
linkes Glycoproteins) family members such as osteopontin (OPN) and dentin matrix protein 1 (DMP1) (Fisher and Fedarko 2003). Like DSP, OPN is expressed in both mineralized and non-mineralized tissues. In mineralized tissues, OPN has been reported in dentin, predentin, bone and cementum (Sodek et al. 2000; Qin et al. 2004; Moses et al. 2006). Both in vitro and in vivo studies have shown that OPN is an effective inhibitor of apatite crystal formation and growth (Boskey et al. 1993, 2002; Hunter et al. 1994; Sodek et al. 2000). DMP1 is processed into $\mathrm{NH}_{2}$-terminal and $\mathrm{COOH}$-terminal domains after translation. The $\mathrm{NH}_{2}$ terminal and $\mathrm{COOH}$-terminal fragments of DMP1 exhibit different distributions in the compartments of rat teeth. The $\mathrm{NH}_{2}$-terminal fragment localizes to predentin, whereas the $\mathrm{COOH}$-terminal domain is mainly restricted to mineralized dentin (Maciejewska et al. 2009). The $\mathrm{NH}_{2}$-terminal and $\mathrm{COOH}$-terminal fragments of DMP1 were reported to have opposite effects on hydroxyapatite formation (Gajjeraman et al. 2007; Tartaix et al. 2004). Thus, it is likely that DSP fragments are also distributed differently among individual compartments of teeth and play different roles during dentinogenesis.

There is a large body of information about DSP expression, characterization and biological functions (Baba et al. 2004a; Butler et al. 1992; Fisher et al. 2004; Kim and Simmer 2007; Qin et al. 2002; Sreenath et al. 2003; Suzuki et al. 2009; Xiao et al. 2001) but little is known about DSP fragments and their expression patterns. To begin to assess the role of DSP and its fragments, we analyzed the expression pattern of DSP in odontoblast-like cells and compared the distribution profiles among $\mathrm{NH}_{2}$-terminal and $\mathrm{COOH}$-terminal fragments of DSP and OPN in mouse mandibular first molars at different ages.

\section{Materials and methods}

\section{Antibodies}

A polyclonal rabbit anti-mouse DSP antibody recognizes residues between ILe ${ }^{18}$ and Lys ${ }^{371}$ as anti-DSP-NH $\mathrm{N}_{2}$ antibody (M300; Santa Cruz Biotechnology, CA, USA) and another polyclonal anti-DSP-COOH antibody was produced in rabbit using the oligopeptide with the sequence of KRNSPKQGESDKPQGTAE (mouse DSP residues ${ }^{401-418}$; Alpha Diagnostic International, San Antonio, TX, USA). Polyclonal goat anti-mouse OPN (R\&D Systems, Minneapolis, MN, USA) was purchased as primary antibody. Normal rabbit immunoglobulin G (IgG) (Santa Cruz Biotechnology) was employed as a negative control for DSP, while normal goat IgG (Santa Cruz Biotechnology) was used as a negative control for OPN. Biotinylated goat anti-rabbit IgG (Vector Laboratories, Burlingame, CA, USA) was used as the secondary antibody for DSP. Biotinylated rabbit anti-goat IgG (Vector Laboratories) was used as the secondary antibody for OPN.

\section{Cell culture}

Mouse differentiated odontoblast-like (MO6-G3) and undifferentiated odontoblast-like (MD10-F2) cells were grown at $33{ }^{\circ} \mathrm{C}$ under $5 \% \mathrm{CO}_{2}$ in an alpha minimum essential medium (a-MEM) supplemented with $10 \%$ fetal calf serum, 100 units $/ \mathrm{ml}$ penicillin/ streptomycin, $50 \mu \mathrm{g} / \mathrm{ml}$ ascorbic acid and $10 \mathrm{mM} \beta$-glycerophosphate (MacDougall et al. 1995).

\section{Western blot analysis}

MO6-G3 and MD10-F2 cells were washed with cold phosphate buffered saline (PBS) and lysed with a RIPA buffer (Santa Cruz Biotechnology). The whole cell lysates were resolved by $7 \%$ SDS-polyacrylamide gel electrophoresis (SDS-PAGE) and transferred to a membrane (Bio-Rad Laboratory, Hercules, CA, USA). Western blot assay was performed as described earlier (Chen et al. 2008) using both DSP antibodies. Goat-anti-mouse $\beta$-actin antibody (Santa Cruz Biotechnology) was used as an internal control. 


\section{Animal and tissue preparation}

The protocol of animal use was approved by the Animal Welfare Committee at the University of Texas Health Science Center at San Antonio. At least three embryos for each time point were sacrificed and taken for the following analyses. At the ages of day 1 (D1), D5, D14, D17 and month 1.4 (M1.4), M2.0, M3.5 and M7.5, C57BL/6 mice were put to death. Mandibles of the mice were immediately dissected and immersed into $4 \%$ paraformaldehyde in a $0.1 \mathrm{M}$ phosphate buffer $(\mathrm{PH} 7.4)$ for 2 days at $4{ }^{\circ} \mathrm{C}$. After washes with PBS, samples were demineralized in $8 \%$ EDTA for $2-8$ weeks. Then, the tissues were processed for paraffin embedding and 5- $\mu \mathrm{m}$ sagittal serial sections were prepared.

\section{Histological staining}

Some of the sections were stained with hematoxylin and eosin (HE).

\section{Immunohistochemistry}

The presence of DSP in MO6-G3 cells and mouse mandibular first molars were analyzed by immunohistochemistry. MO6-G3 cells were cultured on glass slides, rinsed with ice-cold PBS and fixed for $10 \mathrm{~min}$ on ice with methanol/acetone (1:1). Meanwhile, paraffinembedded tissue sections were dewaxed in xylene, hydrated with graded ethanol and incubated with hyaluronidase for $1 \mathrm{~h}$ at $37^{\circ} \mathrm{C}$ to expose the epitopes of target proteins. Then the cells and tissue samples were treated with $0.3 \% \mathrm{H}_{2} \mathrm{O}_{2}$ in methanol solution to inactivate endogenous peroxidase. Afterwards, they were processed with a blocking buffer for $24 \mathrm{~h}$ at $4{ }^{\circ} \mathrm{C}$ to block non-specific binding. Primary antibodies diluted in PBS (1:200 for DSP-NH antibody; 1:50 for DSP-COOH antibody) were applied for $24 \mathrm{~h}$ at $4{ }^{\circ} \mathrm{C}$. Those samples incubated with control IgG instead of first antibody were used as negative controls. Then, biotinylated secondary antibodies were placed on the samples for $1 \mathrm{~h}$ at RT. After washes, they were treated with $\mathrm{ABC}$ solution (Vector Laboratories) for $30 \mathrm{~min}$ at RT and immunopositive loci were detected by incubation with $3,3^{\prime}$-diaminobenzidine tetrahydrochloride. Finally, the samples were counterstained with hematoxylin solution. For OPN, we only performed immunohistochemistry (diluted 1:400 for OPN antibody) in mice from M1.4 to M7.5 as described above.

\section{In situ hybridization}

${ }^{32} \mathrm{P}$-rUTP-labeled antisense riboprobes corresponding to $d s p p$ were generated. The in situ hybridization was performed in mouse mandibular molars at M2.0 and D14 as described previously (Chen et al. 2005).

\section{Results \\ DSP expression in mouse odontoblast-like cells}

To determine DSP expression in mouse odontoblast-like MO6-G3 cells, immunohistochemistry was performed. Figure $1 \mathrm{a}, \mathrm{b}$ shows that DSP was distributed in the cytoplasm and nuclei of MO6-G3 cells. The control slide showed a negative reaction (Fig. $1 c)$.

To further identify expression profiles of DSP fragments in odontoblast-like MO6-G3 and MD-10F2 cells, western blot analysis with whole cell lysates was conducted using both DSP antibodies (Fig. 1d, e). The results showed that multiple lower molecular weight (LMW) bands between 15 and $65 \mathrm{kDa}$ were detected by anti-DSP-NH $\mathrm{N}_{2}$ antibody in both odontoblastlike cell lines and anti-DSP-COOH antibody recognized three LMW DSP bands between 40 and $65 \mathrm{kDa}$ (Fig. 1d, e). 
To exclude the possibility that proteins from the odontoblast-like cells were degraded during protein isolation process, $\beta$-actin was used as an internal control and a band at $42 \mathrm{kDa}$ was identified by western blot (Fig. 1f).

\section{DSP and OPN expression in mouse teeth}

As multiple LMW DSP fragments were observed in mouse odontoblast-like cells (Fig. 1d, e), we next examined whether these fragments of DSP protein were secreted to different parts of mouse teeth at different stages using immunohistochemical assay. Meanwhile, the expression of OPN was also investigated by immunohistochemistry in mouse teeth from M1.4 to M7.5.

D1-At D1, histological analysis showed that the odontoblasts were polarized at the cusp tip region. Deposition of the predentin matrix by the polarized odontoblasts was clearly noticeable and the predentin layer covered up to one half of the height of the central cusp tip. No obvious mineralized dentin was visible (Fig. 2a).

Immunohistochemistry showed that intense staining for anti-DSP- $\mathrm{NH}_{2}$ antibody was observed in the predentin matrix (Fig. 2b), whereas anti-DSP-COOH antibody showed a weak reaction in the predentin matrix (Fig. 2c). Meanwhile, we observed that both antiDSP-NH $\mathrm{N}_{2}$ and anti-DSP-COOH antibodies stained in the secretory odontoblasts, polarized ameloblasts and dental pulp cells (Fig. 2b, c).

D5-At D5, mineralized dentin was formed. There was a clear demarcation between the predentin in pink and mineralized dentin layer in violet (Fig. 2d).

Anti-DSP-NH $\mathrm{N}_{2}$ antibody stained strongly in the predentin, odontoblast layer and pulpal horn and its signal in the mineralized dentin matrix was comparatively weak (Fig. 2e). However, immunoreactions for anti-DSP-COOH antibody were substantially intense in the mineralized dentin matrix at the regions of cusp tips. Dentinal tubules were preferentially stained with anti-DSP-COOH antibody. DSP COOH-terminal fragment(s) was also intensely localized in odontoblasts and pulp tissue immediately beneath odontoblasts (Fig. 2f).

D17-As postnatal development progressed at D17, the mineralized dentin appeared thicker and the formation of the crown is complete. The molars are erupting, covered with a small amount of soft tissues (Fig. 2g, h).

Immunoreactions for anti-DSP- $\mathrm{NH}_{2}$ antibody were intense in predentin, odontoblasts, dental pulp and relatively weak in mineralized dentin (Fig. 2g, i). For anti-DSP-COOH antibody, there was a substantially higher level of positive reactions in dentinal tubules of the mineralized dentin, although weak immunoreactions were detected in predentin, odontoblasts and dental pulp (Fig. $2 \mathrm{~h}, \mathrm{j}$ ).

M1.4-At M1.4, the first molars had already reached the functional occlusion. There was a small amount of attrition at the central cusp tips. No obvious RD was observed (Fig. 3a, b).

The anti-DSP- $\mathrm{NH}_{2}$ antibody stained strongly in the predentin, odontoblasts and dental pulp cells beneath the cusps but weakly in mineralized dentin (Fig. 3c, d). In contrast, the immunoreactivity for the anti-DSP-COOH antibody appeared to concentrate in the mineralized dentin but weakly in predentin, odontoblasts and dental pulp cells (Fig. 3e, f).

At this stage, OPN expression was clearly observed within odontoblasts and predentin. Most dentin showed no positive reaction for OPN antibody; occasionally, slight positive staining 
was observed in dentinal tubules extending through the predentin into dentin. In contrast, bone, periodontal ligament and cementum gave intense signals for OPN (Fig. 3g, h).

M3.5 and M7.5-In the specimens at M3.5, RD formation had begun and was limited to locations where dentinal tubules appeared to communicate with the areas of attrition at the cusp tips. The RD was easily distinguishable from dentin. The border between dentin and $\mathrm{RD}$ was typically demarcated by a variation in the orientation of the dentinal tubules (Fig. $4 a, b)$. As the age of the mice increased at M7.5, the teeth worn more severely and the relative amount of RD increased (Fig. 5a, b).

No signal was detected in the negative control sections, where normal IgG was used instead of the primary antibodies (Fig. 4a, b).

Like 1.4 M, from M3.5 to M7.5, the distribution difference between DSP $\mathrm{NH}_{2}$ - and $\mathrm{COOH}$ terminal fragments in the mouse teeth exhibited the same pattern. The DSP $\mathrm{NH}_{2}$-terminal fragment(s) was primarily localized in the predentin, odontoblasts and dental pulp cells (Figs. 4c, d and 5c, d), whereas the DSP COOH-terminal domain accumulated in dentinal tubules appearing as stripes (Figs. $4 \mathrm{e}, \mathrm{f}$ and $5 \mathrm{e}, \mathrm{f}$ ). Compared to predentin and dentin, RD showed much lower expression levels of both $\mathrm{DSP} \mathrm{NH}_{2}$ - and $\mathrm{COOH}$-terminal fragments (Figs. $4 \mathrm{c}-\mathrm{f}$ and $5 \mathrm{c}-\mathrm{f}$ ).

From $3.5 \mathrm{M}$ to $7.5 \mathrm{M}$, OPN was clearly positive in RD as well as predentin, bone, periodontal ligament and cementum. On the contrary, dentin showed only a very little positive reaction for OPN in dentinal tubules extending through RD and predentin to dentin under the cusp tips (Figs. 4g, h and 5g, h).

In addition to teeth, $\mathrm{DSP} \mathrm{NH}_{2}$-terminal and $\mathrm{COOH}$-terminal domains were also observed in the periodontal ligament but at a low level (Figs. 3c, e, 4c, e and 5c, e). In situ hybridization assay confirmed the weak $d s p p$ mRNA expression in the periodontal ligament at M2.0 (Electronic Supplementary Material, Fig. S1a, b, e). At an earlier stage (D14), dspp mRNAwas also weakly expressed in the immature periodontal ligament (Electronic Supplementary Material, Fig. S1c, d).

\section{Discussion}

In this study, to gain insights of the role of DSP fragments in dentinogenesis, we investigated the expression of DSP in odontoblast-like cells and compared the expression patterns between DSP $\mathrm{NH}_{2}$-terminal and $\mathrm{COOH}$-terminal fragments in mouse molars from D1 to M7.5. The localization profiles of DSP fragments in molars were also compared with that of OPN from M1.4 to M7.5. Our results showed that LMW DSP fragments were present in the odontoblast-like cells and the $\mathrm{NH}_{2}$-terminal and $\mathrm{COOH}$-terminal fragments of DSP localized differently in the mouse teeth. Furthermore, the expression pattern of DSP differed sharply from that of OPN in RD. Analyses of these data suggest that: (1) a part of the fulllength DSP is processed into fragments in odontoblast-like cells; (2) DSP fragments are essential for the dentin assembly process and different DSP fragments may play distinct roles during dentinogenesis; and (3) compared with OPN, DSP is less critical for RD formation.

To date, most DSP immunostaining studies have seemed to focus on full-length DSP (Baba et al. 2004a, b; Hao et al. 2009; Moses et al. 2006). To the best of our knowledge, we have for the first time described the distribution of the DSP $\mathrm{NH}_{2}$-terminal and $\mathrm{COOH}$-terminal fragments in odontoblast-like cells and mouse teeth. 
At D1, the odontoblasts were highly polarized and actively involved in the synthesis of ECM. Intense immunoreactions for DSP were observed in odontoblasts and ameloblasts (Fig. 2b, c), which was consistent with the previous study (Hao et al. 2009). DSP expression in ameloblasts suggested that it might be involved in ameloblast differentiation and enamel formation. Previous studies reported that overexpression of DSP in mouse ameloblasts significantly increased the rate of enamel formation and enamel hardness (Paine et al. 2005; White et al. 2007), suggesting that DSP secreted by ameloblasts might contribute to the mechanical properties of the dentin-enamel junction. At this stage, no mineralized dentin was formed. Interestingly, the non-mineralized predentin stained almost exclusively with the anti-DSP-NH $\mathrm{N}_{2}$ antibody (Fig. 2b), whereas anti-DSP-COOH antibody showed very weak staining in predentin (Fig. 2c). At D5, mineralization of the dentin matrix was formed (Fig. 2d) and the difference of the immunolocalization between the anti-DSP-NH $\mathrm{N}_{2}$ and anti-DSP$\mathrm{COOH}$ antibodies in the mineralized dentin was prominent. Dentin at the cusp region stained strongly with anti-DSP-COOH antibody (Fig. 2f) but weakly with anti-DSP-NH antibody (Fig. 2e). In the maturing teeth at D17, dentin and enamel formation of the molar crown was essentially complete. The expression levels of DSP in odontoblasts (Fig. 2g-j) were found to be downregulated compared with that at D1 and D5 (Fig. 2b, c, e, f), which might reflect a reduced secretory activity of odontoblasts and was in accordance with the slower rate of dentin matrix deposition.

From D17 to the end of the experiment (M7.5), anti-DSP- $\mathrm{NH}_{2}$ antibody stained strongly in non-mineralized predentin but weakly in mineralized dentin (Figs. 2g, i, 3c, d, 4c, d and 5c, d). This expression pattern also applies to the NH2-terminal fragment of DMP1

(Maciejewska et al. 2009), which was able to inhibit hydroxyapaptite formation in vitro (Gajjeraman et al. 2007). We postulated that the DSP $\mathrm{NH}_{2}$-terminal fragment(s) secreted into the predentin, along with the proteoglycan form of the DMP1 $\mathrm{NH}_{2}$-terminal fragment and other proteoglycans, prevented this tissue from being mineralized too rapidly and kept the uniform width of the predentin throughout its life. Before the mineralization of the collagen fibrils and the conversion of the predentin to dentin, a major portion of the DSP $\mathrm{NH}_{2}$-terminal fragment(s) was metabolized or removed. Thus, there was comparatively little DSP $\mathrm{NH}_{2}$-terminal fragment(s) in the mineralized dentin.

From D17 to M7.5, the COOH-terminal fragment(s) of DSP was present in the mineralized areas of dentin (Figs. 2h, j, 3e, f, 4e, f and 5e, f), which aligns with the previously reported immunodistribution of DSP in dentin (Baba et al. 2004b; Moses et al. 2006; Suzuki et al. 2009). The strong and consistent immunoreactions for anti-DSP-COOH antibody in mineralized dentin suggest that DSP COOH-terminal fragment(s) may be involved in the maintenance of the mineralized tissue microenvironment. In the older groups, the levels of DSP increased with age, which is most notable when comparing the 3.5-month (Fig. 4e, f) and 7.5-month (Fig. 5e, f) samples. This might be a response by odontoblasts to mechanical stress from occlusal forces (Baba et al. 2004b). Staining of anti-DSP-COOH antibody showed the stripe-like appearance (Figs. 2j, 3f, $4 \mathrm{f}$ and $5 \mathrm{f}$ ), suggesting that the peritubular dentin might stain stronger compared with the intertubular dentin.

In teeth, the expression pattern of DSP COOH-terminal fragment(s) was similar to that of DMP1 COOH-terminal fragment, which was confirmed to act as a promoter for dentin mineralization (Gajjeraman et al. 2007; Maciejewska et al. 2009; Tartaix et al. 2004). This evidence provided indirect support to the hypothesis that the $\mathrm{COOH}$-terminal fragment of DSP promoted biomineralization of dentin. Although DSP has been reported to have limited effects on in vitro formation and growth of hydroxyapatite crystals (Boskey et al. 2000), transgenic expression of DSP in DSPP null background mice resulted in a partial rescue of the DSPP null phenotype with an absence of irregular unmineralized areas in dentin and less frequent pulp exposure. These results in vivo confirmed that dentinal DSP might facilitate 
initiation of hydroxyapatite formation along or inside the collagen fibril, leading to conversion of the predentin to dentin at the mineralization front (Suzuki et al. 2009), consistent with our hypothesis about the probable function of DSP COOH-terminal fragment(s). The discrepancy of the role of DSP in mineralization might partially be explained by the post-translational modifications of DSP protein, such as glycosylation (Qin et al. 2003b; Yamakoshi et al. 2005; Suzuki et al. 2009; Zhu et al. 2010) and proteolytic processing that only occurs in vivo.

In porcine molars, DSP is further cleaved on the $\mathrm{NH}_{2}$-terminal sides of $\mathrm{Thr}^{200}, \mathrm{Ser}^{330}$, $\mathrm{Val}^{353}$, $\mathrm{Leu}^{360}, \mathrm{Ile}^{362}$ and $\mathrm{Ser}^{377}$, among which three locations have been characterized as cleavage sites by MMP2 and MMP20 (Yamakoshi et al. 2006; Yamakoshi 2009). MMP inhibition deregulated the processing of DSP, caused an increase in the total content of DSP and altered the mineralization of mouse tooth germs (Bourd-Boittin et al. 2005). Our previous studies showed that MMP9 is able to catalyze mouse recombinant DSP protein into three major fragments in vitro. Furthermore, using mouse $\mathrm{DSP} \mathrm{NH}_{2}$ - and $\mathrm{COOH}$-terminal antibodies, we found that MMP9 cleaves DSP into the $\mathrm{NH}_{2}$ - and $\mathrm{COOH}$-terminal fragments (Yuan et al. 2009a, b; unpublished observations). Although the exact cleavage sites of mouse DSP in vivo is as yet undetermined, the different expression profiles of anti-DSP$\mathrm{NH}_{2}$ and anti-DSP-COOH antibodies in this study confirmed that DSP was catalyzed into fragments in mouse teeth. The $\mathrm{NH}_{2}$-terminal and $\mathrm{COOH}$-terminal fragments of DSP tended to separate in the predentin and dentin, confirming that part of DSP is processed in odontoblasts. This is coincident with our observations that DSP was processed into fragments within two mouse odontoblast-like cells before being secreted (Fig. 1; Chen et al. 2008). The further cleavage of DSP and resistance of DPP to digestion by proteases (Yamakoshi et al. 2006) can partially explain why DPP is more abundant than DSP in the mineralized dentin (Butler 1998).

From 3.5 M to 7.5 M, RD was observed and its relative amount increased with age (Figs. 4a, $\mathrm{b}$ and $5 \mathrm{a}, \mathrm{b})$. The expression levels of DSP in RD were much lower than in predentin and dentin (Figs. 4d, f and 5d, f). TGF $\beta 1$ was able to downregulate DSP(P) expression in odontoblast-like cell lines through Smad signaling and has been implicated in the regulation of dental tissue repair through reactionary or reparative dentinogenesis (He et al. 2004; Hwang et al. 2008; Thyagarajan et al. 2001; Unterbrink et al. 2002). Thus, during the formation of $\mathrm{RD}$, in response to abrasion, TGF $\beta 1$ may be released from its endogenous pool in dentin matrix and pulpal cells (Hwang et al. 2008) and be responsible for the low expression level of DSP in RD. In contrast, OPN antibody showed a strong staining in RD (Figs. $4 \mathrm{~h}$ and $5 \mathrm{~h}$ ). OPN was also reported to be induced in pathological mineralization such as kidney stone formation (Kohri et al. 1993). The intense expression of OPN in RD suggested that OPN might be essential for RD formation. Under the influence of attrition, the odontoblasts were secreting more OPN to form RD for protection of themselves from the harmful external stimuli. We also found that OPN was consistently highly expressed in predentin (Figs. 3h, 4h and 5h) from M1.4 to M7.5, in agreement with the previous study (Moses et al. 2006). OPN is an effective inhibitor of mineral formation, mineral crystal growth and proliferation (Boskey et al. 2002). The colocalization of DSP $\mathrm{NH}_{2}$-terminal fragment(s) and OPN in predentin suggested that they may work in concert to keep the predentin from too rapid mineralization.

The expression of DSP in periodontal ligament (Figs. 3, 4 and 5; Electronic Supplementary Material, Fig. S1) was consistent with the previous study (Baba et al. 2004a), suggesting that DSP might play a role for the formation and homeostasis of periodontal ligament.

Taken together, part of the full-length DSP was processed into fragments in the odontoblastlike cells, which might also occur in odontoblasts in vivo. Then the fragments of DSP in the 
odontoblasts were secreted to different parts of mouse teeth. DSP $\mathrm{NH}_{2}$-terminal fragment(s) was highly localized in predentin, whereas the $\mathrm{COOH}$-terminal DSP was mainly restricted to mineralized dentin. Until now, the biological roles of DSP fragments in dentinogenesis have not been reported. The clear differences in the distribution of DSP fragments provide new information and clues about their potentially different roles in dentinogenesis. It seems very likely that the counterbalancing effect of the DSP fragments plays an important role in the appropriate biomineralization of dentin. Further investigations are needed to determine the exact cleavage sites of mouse DSP and to provide deeper insights into the precise roles of DSP fragments in dentinogenesis.

\section{Supplementary Material}

Refer to Web version on PubMed Central for supplementary material.

\section{Acknowledgments}

This study was supported by grants from the National Natural Science Foundation of China (No. 81000436 and 81000418), the Fundamental Research Funds for the Central Universities (No. 4901049) and NIDCR (RO1 DE019892).

\section{References}

Baba O, Qin C, Brunn JC, Jones JE, Wygant JN, McIntyre BW, Butler WT. Detection of dentin sialoprotein in rat periodontium. Eur J Oral Sci. 2004a; 112:163-710. [PubMed: 15056114]

Baba O, Qin C, Brunn JC, Wygant JN, McIntyre BW, Butler WT. Colocalization of dentin matrix protein 1 and dentin sialoprotein at late stages of rat molar development. Matrix Biol. 2004b; 23:371-379. [PubMed: 15533758]

Begue-Kirn C, Ruch JV, Ridall AL, Butler WT. Comparative analysis of mouse DSP and DPP expression in odontoblasts, preameloblasts, and experimentally induced odontoblast-like cells. Eur J Oral Sci. 1998; 106(Suppl 1):254-259. [PubMed: 9541234]

Bleicher F, Couble ML, Farges JC, Couble P, Magloire H. Sequential expression of matrix protein genes in developing rat teeth. Matrix Biol. 1999; 18:133-143. [PubMed: 10372553]

Boskey AL, Maresca M, Ullrich W, Doty SB, Butler WT, Prince CW. Osteopontin-hydroxyapatite interactions in vitro: inhibition of hydroxyapatite formation and growth in a gelatin gel. Bone Miner. 1993; 22:147-159. [PubMed: 8251766]

Boskey A, Spevak L, Tan M, Doty SB, Butler WT. Dentin sialoprotein (DSP) has limited effects on in vitro apatite formation and growth. Calcif Tissue Int. 2000; 67:472-478. [PubMed: 11289697]

Boskey AL, Spevak L, Paschalis E, Doty SB, McKee MD. Osteopontin deficiency increases mineral content and mineral crystallinity in mouse bone. Calcif Tissue Int. 2002; 71:145-154. [PubMed: 12073157]

Bourd-Boittin K, Fridman R, Fanchon S, Septier D, Goldberg M, Menashi S. Matrix metalloproteinase inhibition impairs the processing, formation and mineralization of dental tissues during mouse molar development. Exp Cell Res. 2005; 304:493-505. [PubMed: 15748894]

Bronckers AL, D’Souza RN, Butler WT, Lyaruu DM, van Dijk S, Gay S, Wöltgens JH. Dentin sialoprotein: biosynthesis and developmental appearance in rat tooth germs in comparison with amelogenins, osteocalcin and collagen type-I. Cell Tissue Res. 1993; 272:237-247. [PubMed: 8513478]

Butler WT. Dentin matrix proteins. Eur J Oral Sci. 1998; 106(Suppl 1):204-210. [PubMed: 9541227]

Butler WT, Bhown M, Brunn JC, D’Souza RN, Farach-Carson MC, Happonen RP, Schrohenloher RE, Seyer JM, Somerman MJ, Foster RA, et al. Isolation, characterization and immunolocalization of a 53-kDal dentin sialoprotein (DSP). Matrix. 1992; 12:343-351. [PubMed: 1484502]

Chen S, Rani S, Wu Y, Unterbrink A, Gu TT, Gluhak-Heinrich J, Chuang HH, Macdougall M. Differential regulation of dentin sialophosphoprotein expression by Runx 2 during odontoblast cytodifferentiation. J Biol Chem. 2005; 280:29717-29727. [PubMed: 15980071] 
Chen S, Chen L, Jahangiri A, Chen B, Wu Y, Chuang HH, Qin C, MacDougall M. Expression and processing of small integrin-binding ligand $\mathrm{N}$-linked glycoproteins in mouse odontoblastic cells. Arch Oral Biol. 2008; 53:879-889. [PubMed: 18582847]

D’Souza RN, Bronckers AL, Happonen RP, Doga DA, Farach-Carson MC, Butler WT. Developmental expression of a $53 \mathrm{KD}$ dentin sialoprotein in rat tooth organs. J Histochem Cytochem. 1992; 40:359-366. [PubMed: 1552175]

Fisher LW, Fedarko NS. Six genes expressed in bones and teeth encode the current members of the SIBLING family of proteins. Connect Tissue Res. 2003; 44(Suppl 1):33-40. [PubMed: 12952171]

Fisher LW, Jain A, Tayback M, Fedarko NS. Small integrin binding ligand N-linked glycoprotein gene family expression in different cancers. Clin Cancer Res. 2004; 10:8501-8511. [PubMed: $15623631]$

Gajjeraman S, Narayanan K, Hao J, Qin C, George A. Matrix macromolecules in hard tissues control the nucleation and hierarchical assembly of hydroxyapatite. J Biol Chem. 2007; 282:1193-1204. [PubMed: 17052984]

Goldberg M, Smith AJ. Cells and Extracellular Matrices of Dentin and Pulp: a Biological Basis for Repair and Tissue Engineering. Crit Rev Oral Biol Med. 2004; 15:13-27. [PubMed: 14761897]

Hao J, Ramachandran A, George A. Temporal and spatial localization of the dentin matrix proteins during dentin biomineralization. J Histochem Cytochem. 2009; 57:227-237. [PubMed: 19001636]

He WX, Niu ZY, Zhao SL, Jin WL, Gao J, Smith AJ. TGF-beta activated Smad signalling leads to a Smad3-mediated down-regulation of DSPP in an odontoblast cell line. Arch Oral Biol. 2004; 49:911-918. [PubMed: 15353247]

Hunter GK, Kyle CL, Goldberg HA. Modulation of crystal formation by bone phosphoproteins: structural specificity of the osteopontin-mediated inhibition of hydroxyapatite formation. Biochem J. 1994; 300:723-728. [PubMed: 8010953]

Hwang YC, Hwang IN, Oh WM, Park JC, Lee DS, Son HH. Influence of TGF-beta1 on the expression of BSP, DSP, TGF-beta1 receptor I and Smad proteins during reparative dentinogenesis. J Mol Histol. 2008; 39:153-160. [PubMed: 17929179]

Kim JW, Simmer JP. Hereditary dentin defects. J Dent Res. 2007; 86:392-399. [PubMed: 17452557]

Kohri K, Nomura S, Kitamura Y, Nagata T, Yoshioka K, Iguchi M, Yamate T, Umekawa T, Suzuki Y, Sinohara $\mathrm{H}$, et al. Structure and expression of the mRNA encoding urinary stone protein (osteopontin). J Biol Chem. 1993; 268:15180-15184. [PubMed: 8325891]

MacDougall M, Thiemann F, Ta H, Hsu P, Chen LS, Snead ML. Temperature sensitive simian virus 40 large T antigen immortalization of murine odontoblast cell cultures: establishment of clonal odontoblast cell line. Connect Tissue Res. 1995; 33:97-103. [PubMed: 7554969]

MacDougall M, Simmons D, Luan X, Nydegger J, Feng J, Gu TT. Dentin phosphoprotein and dentin sialoprotein are cleavage products expressed from a single transcript coded by a gene on human chromosome 4. Dentin phosphoprotein DNA sequence determination. J Biol Chem. 1997; 272:835-842. [PubMed: 8995371]

Maciejewska I, Cowan C, Svoboda K, Butler WT, D’Souza R, Qin C. The NH2-terminal and COOHterminal fragments of dentin matrix protein 1 (DMP1) localize differently in the compartments of dentin and growth plate of bone. J Histochem Cytochem. 2009; 57:155-166. [PubMed: 18854597]

Moses KD, Butler WT, Qin C. Immunohistochemical study of small integrin-binding ligand, N-linked glycoproteins in reactionary dentin of rat molars at different ages. Eur J Oral Sci. 2006; 114:216222. [PubMed: 16776771]

Ogbureke KU, Fisher LW. Expression of SIBLINGs and their partner MMPs in salivary glands. J Dent Res. 2004; 83:664-670. [PubMed: 15329369]

Paine ML, Luo W, Wang HJ, Bringas P Jr, Ngan AY, Miklus VG, Zhu DH, MacDougall M, White $\mathrm{SN}$, Snead ML. Dentin sialo-protein and dentin phosphoprotein overexpression during amelogenesis. J Biol Chem. 2005; 280:31991-31998. [PubMed: 16014627]

Prasad M, Zhu Q, Sun Y, Wang X, Kulkarni A, Boskey A, Feng JQ, Qin C. Expression of dentin sialophosphoprotein in non-mineralized tissues. J Histochem Cytochem. 2011; 59:1009-1021. [PubMed: 22043023] 
Qin C, Brunn JC, Cadena E, Ridall A, Tsujigiwa H, Nagatsuka H, Nagai N, Butler WT. The expression of dentin sialophosphoprotein gene in bone. J Dent Res. 2002; 81:392-394. [PubMed: 12097430]

Qin C, Brunn JC, Cadena E, Ridall A, Butler WT. Dentin sialoprotein in bone and dentin sialophosphoprotein gene expressed by osteoblasts. Connect Tissue Res. 2003a; 44(Suppl 1):179_ 183. [PubMed: 12952194]

Qin C, Brunn JC, Baba O, Wygant JN, McIntyre BW, Butler WT. Dentin sialoprotein isoforms: detection and characterization of a high molecular weight dentin sialoprotein. Eur J Oral Sci. 2003b; 111:235-242. [PubMed: 12786955]

Qin C, Baba O, Butler WT. Post-translational modifications of sibling proteins and their roles in osteogenesis and dentinogenesis. Crit Rev Oral Biol Med. 2004; 15:126-136. [PubMed: 15187031]

Rajpar MH, Koch MJ, Davies RM, Mellody KT, Kielty CM, Dixon MJ. Mutation of the signal peptide region of the bicistronic gene DSPP affects translocation to the endoplasmic reticulum and results in defective dentine biomineralization. Hum Mol Genet. 2002; 11:2559-2565. [PubMed: 12354781]

Ritchie HH, Hou H, Veis A, Butler WT. Cloning and sequence determination of rat dentin sialoprotein, a novel dentin protein. J Biol Chem. 1994; 269:3698-3702. [PubMed: 8106414]

Ritchie HH, Pinero GJ, Hou H, Butler WT. Molecular analysis of rat dentin sialoprotein. Connect Tissue Res. 1995; 33:73-79. [PubMed: 7554965]

Ritchie HH, Shigeyama Y, Somerman MJ, Butler WT. Partial cDNA sequencing of mouse dentine sialoprotein and detection of its specific expression by odontoblasts. Arch Oral Biol. 1996; 41:571-575. [PubMed: 8937648]

Sodek J, Ganss B, Mckee MD. Osteopontin. Crit Rev Oral Biol Med. 2000; 11:279-303. [PubMed: 11021631]

Sreenath T, Thyagarajan T, Hall B, Longenecker G, D’Souza R, Hong S, Wright JT, MacDougall M, Sauk J, Kulkarni AB. Dentin sialophosphoprotein knockout mouse teeth display widened predentin zone and develop defective dentin mineralization similar to human dentinogenesis imperfecta type III. J Biol Chem. 2003; 278:24874-24880. [PubMed: 12721295]

Sun Y, Ma S, Zhou J, Yamoah AK, Feng JQ, Hinton RJ, Qin C. Distribution of small integrin-binding ligand, N-linked glycoproteins (SIBLING) in the articular cartilage of the rat femoral head. $\mathrm{J}$ Histochem Cytochem. 2010a; 58:1033-1043. [PubMed: 20679519]

Sun Y, Lu Y, Chen S, Prasad M, Wang X, Zhu Q, Zhang J, Ball H, Feng J, Butler WT, Qin C. Key proteolytic cleavage site and full-length form of DSPP. J Dent Res. 2010b; 89:498-503. [PubMed: 20332332]

Suzuki S, Sreenath T, Haruyama N, Honeycutt C, Terse A, Cho A, Kohler T, Müller R, Goldberg M, Kulkarni AB. Dentin sialoprotein and dentin phosphoprotein have distinct roles in dentin mineralization. Matrix Biol. 2009; 28:221-229. [PubMed: 19348940]

Tang XN, Zhu YQ, Marcelo CL, Ritchie HH. Expression of mineralized tissue associated proteins: Dentin sialoprotein and phosphophoryn in rodent hair follicles. J Dermatol Sci. 2011; 64:92-98. [PubMed: 21908176]

Tartaix PH, Doulaverakis M, George A, Fisher LW, Butler WT, Qin C, Salih E, Tan M, Fujimoto Y, Spevak L, Boskey AL. In vitro effects of dentin matrix protein-1 on hydroxyapatite formation provide insights into in vivo functions. J Biol Chem. 2004; 279:18115-18120. [PubMed: 14769788]

Thyagarajan T, Sreenath T, Cho A, Wright JT, Kulkarni AB. Reduced expression of dentin sialophosphoprotein is associated with dysplastic dentin in mice overexpressing transforming growth factor-beta 1 in teeth. J Biol Chem. 2001; 276:11016-11020. [PubMed: 11116156]

Unterbrink A, O'Sullivan M, Chen S, MacDougall M. TGF beta-1 downregulates DMP-1 and DSPP in odontoblasts. Connect Tissue Res. 2002; 43:354-358. [PubMed: 12489180]

White SN, Paine ML, Ngan AY, Miklus VG, Luo W, Wang H, Snead ML. Ectopic expression of dentin sialoprotein during amelogenesis hardens bulk enamel. J Biol Chem. 2007; 282:5340-5345. [PubMed: 17189271] 
Xiao S, Yu C, Chou X, Yuan W, Wang Y, Bu L, Fu G, Qian M, Yang J, Shi Y, Hu L, Han B, Wang Z, Huang W, Liu J, Chen Z, Zhao G, Kong X. Dentinogenesis imperfecta 1 with or without progressive hearing loss is associated with distinct mutations in DSPP. Nat Genet. 2001; 27:201204. [PubMed: 11175790]

Yamakoshi Y. Dentinogenesis and Dentin Sialophosphoprotein (DSPP). J Oral Biosci. 2009; 51:134. [PubMed: 20157636]

Yamakoshi Y, Hu JC, Fukae M, Iwata T, Kim JW, Zhang H, Simmer JP. Porcine dentin sialoprotein is a proteoglycan with glycosaminoglycan chains containing chondroitin 6-sulfate. J Biol Chem. 2005; 280:1552-1560. [PubMed: 15537641]

Yamakoshi Y, Hu JC, Iwata T, Kobayashi K, Fukae M, Simmer JP. Dentin sialophosphoprotein is processed by MMP-2 and MMP-20 in vitro and in vivo. J Biol Chem. 2006; 281:38235-38243. [PubMed: 17046814]

Yuan G, Wang Y, Gluhak-Heinrich J, Yang G, Chen L, Li T, Wu LA, Chen Z, MacDougall M, Chen S. Tissue-specific expression of dentin sialophosphoprotein (DSPP) and its polymorphisms in mouse tissues. Cell Biol Int. 2009a; 33:816-829. [PubMed: 19450697]

Yuan, G.; Yang, G.; Gonzalez, O.; Gluahk-Heinrich, J.; Xu, X.; Chen, Z.; Steffensen, B.; Donly, K.; MacDougall, M.; Chen, Z.; Chen, S. Tooth defects and DSP/DSPP processing interference in MMP-9 knock out mice. 89th General Session and Exhibition of the IADR; 2009. p. 126

Zhu Q, Sun Y, Prasad M, Wang X, Yamoah AK, Li Y, Feng J, Qin C. Glycosaminoglycan chain of dentin sialoprotein proteoglycan. J Dent Res. 2010; 89:808-812. [PubMed: 20400719] 


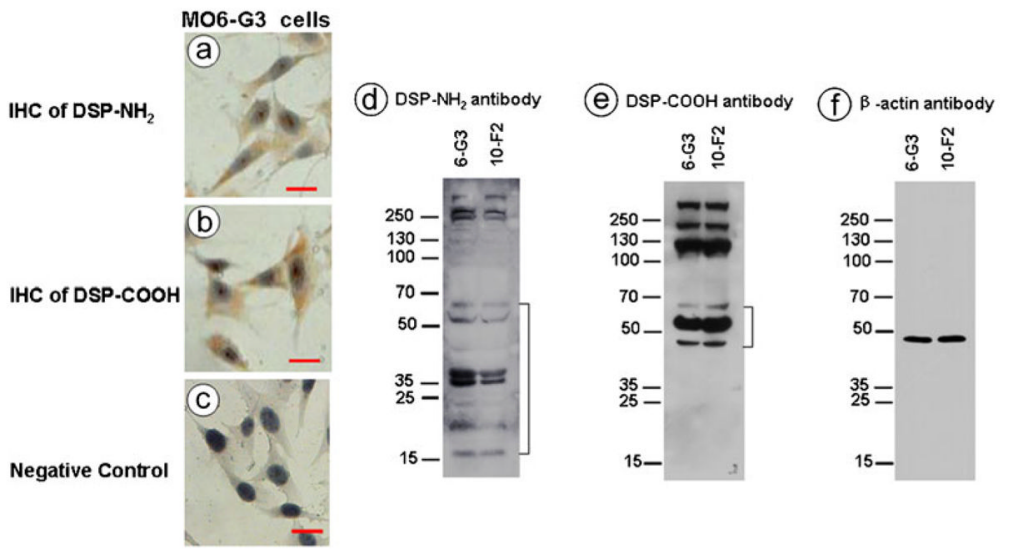

Fig. 1.

DSP expression in the mouse odontoblast-like cells. a, b Expression of DSP protein in MO6-G3 cells was analyzed by immunohistochemistry using anti-DSP-NH $\mathrm{N}_{2}$ and anti-DSP$\mathrm{COOH}$ antibodies. DSP expression was observed in both the cytoplasm and nuclei of the cells. c Negative control using normal rabbit IgG. d, e Western blot analysis of DSP expression patterns in MO6-G3 and MD10-F2 cells. Multiple LMW DSP fragments between 15 and $65 \mathrm{kDa}$ were detected by anti-DSP-NH $\mathrm{N}_{2}$ antibody in both odontoblast-like cell lines (d, bracket) and anti-DSP-COOH antibody recognized three LMW DSP bands between 40 and $65 \mathrm{kDa}(\mathbf{e}$, bracket). f $\beta$-actin was used as an internal control. 6-G3 and 10F2 represent MO6-G3 and MD10-F2 cells, respectively. Bars $20 \mu \mathrm{m}$ 




Fig. 2.

HE staining and immunolocalization of anti-DSP-NH $\mathrm{NH}_{2}$ and anti-DSP-COOH antibodies in mouse molars at $D 1(\mathbf{a}-\mathbf{c}), D 5(\mathbf{d}-\mathbf{f})$ and $D 17(\mathbf{g}-\mathbf{j})$. a HE staining of the first mandibular molar at D1. Predentin $(*)$ is in light pink. b Intense immunodistribution of anti-DSP-NH antibody was detected in predentin $(*)$, odontoblasts, ameloblasts and dental pulp. c AntiDSP-COOH antibody showed strong reactions in odontoblasts, ameloblasts and dental pulp but weak in predentin (*). d HE staining of mouse molar organ at D5. Predentin (*) is in light pink. Dentin is in violet. e, $\mathbf{f}$ At D5, immunostaining for anti-DSP- $\mathrm{NH}_{2}$ antibody was strong in predentin (*) and weak in dentin (e). However, anti-DSP-COOH antibody showed strong reactions in dentin and appeared as stripes $(\mathbf{f})$. $\mathbf{g}-\mathbf{j}$ At D17, predentin $(*)$, odontoblasts and dental pulp stained strongly with anti-DSP- $\mathrm{NH}_{2}$ antibody $(\mathbf{g}, \mathbf{i})$. Mineralized dentin stained substantially stronger with anti-DSP-COOH antibody $(\mathbf{h}, \mathbf{j})$ compared to anti-DSP$\mathrm{NH}_{2}$ antibody. $D$ dentin, $O d$ odontoblasts, $A m$ ameloblasts. Bars $(\mathbf{a}-\mathbf{c}, \mathbf{i}, \mathbf{j}) 50 \mu \mathrm{m},(\mathbf{d}-\mathbf{f}) 100$ $\mu \mathrm{m},(\mathbf{g}, \mathbf{h}) 500 \mu \mathrm{m}$ 


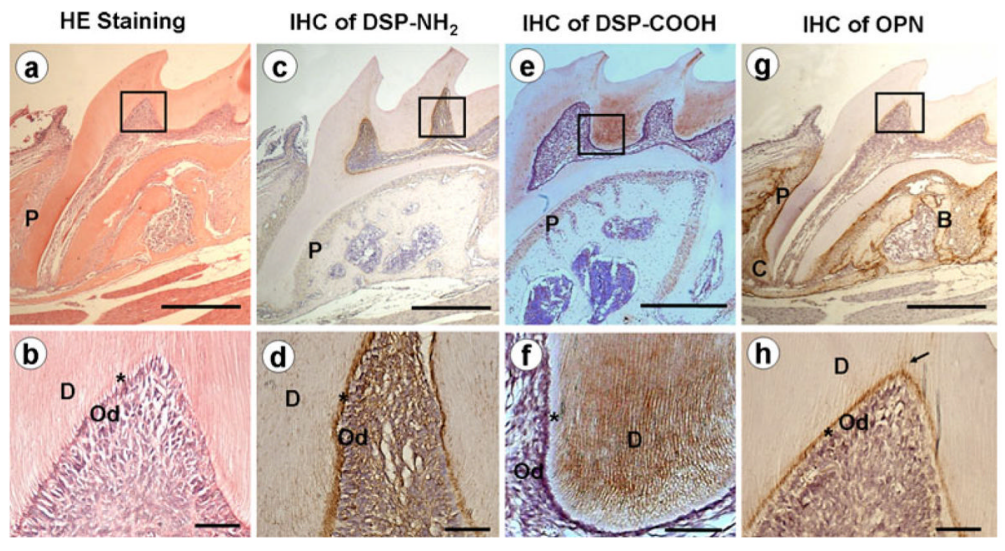

Fig. 3.

$\mathrm{HE}$ staining, and immunolocalization of DSP $\mathrm{NH}_{2}$-terminal, $\mathrm{COOH}$-terminal fragments and OPN in mouse molars at M1.4. a, b HE staining showed the configuration of the molar. $\mathbf{c}, \mathbf{d}$ DSP $\mathrm{NH}_{2}$-terminal fragment was mainly localized in predentin (*), odontoblasts and dental pulp. e, $\mathbf{f}$ The immunoreactions for anti-DSP-COOH antibody accumulated in mineralized dentin. g, h Predentin (*), periodontal ligament, cellualar cementum, mantle dentin of the roots and bone gave intense positive signals for OPN. OPN was weakly positive in some of the dentinal tubules extending through predentin to dentin (arrow). b, $\mathbf{d}, \mathbf{f}, \mathbf{h}$ Higher magnification of the rectangles in $(\mathbf{a}, \mathbf{c}, \mathbf{e}, \mathbf{g})$. $D$ dentin, $O d$ odontoblasts, $P$ periodontal ligament, $B$ bone, $C$ cementum. Bars $(\mathbf{a}, \mathbf{c}, \mathbf{e}, \mathbf{g}) 500 \mu \mathrm{m},(\mathbf{b}, \mathbf{d}, \mathbf{f}, \mathbf{h}) 50 \mu \mathrm{m}$ 
Negative Control
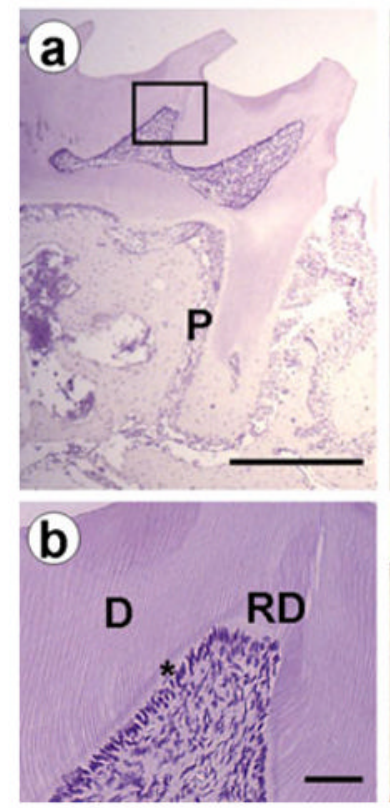
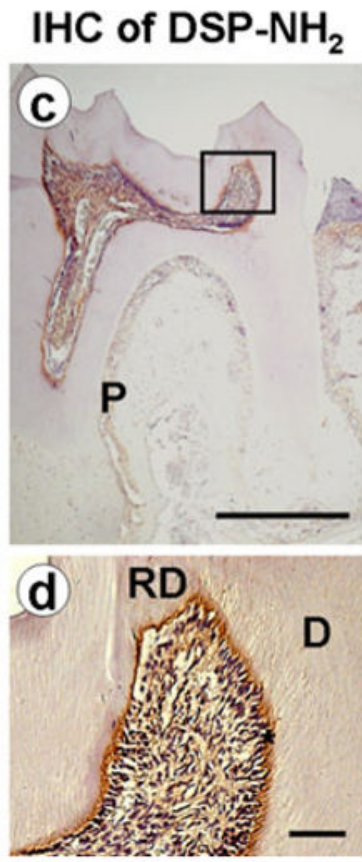

IHC of DSP-COOH


IHC of OPN
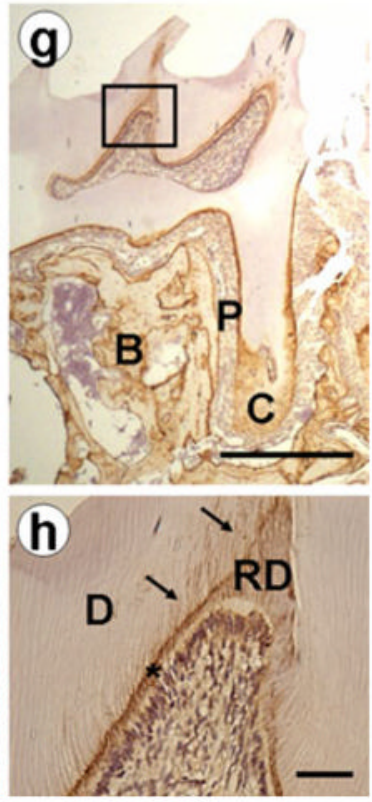

Fig. 4.

Immunolocalization of DSP $\mathrm{NH}_{2}$-terminal, $\mathrm{COOH}$-terminal fragments and OPN in mouse molars at M3.5. a, b Control slides, which were incubated with normal IgG instead of first antibodies, showed a negative reaction. Reactionary dentin $(R D)$ was formed beneath the areas of cusp attrition. $\mathbf{c}$, $\mathbf{d}$ The DSP $\mathrm{NH}_{2}$-terminal fragment(s) was intensely expressed in predentin $(*)$, odontoblasts and dental pulp but weak in dentinal tubules and RD. e, $\mathbf{f}$ The DSP COOH-terminal fragment showed intense immunodistribution in dentinal tubules but weak in RD. $\mathbf{g}, \mathbf{h}$ OPN was highly expressed in RD as well as predentin (*), mantle dentin of the roots, periodontal ligament, cementum and bone but weakly in dentin (arrows). b, d, f, h Higher magnification of the rectangles in $(\mathbf{a}, \mathbf{c}, \mathbf{e}, \mathbf{g})$. D dentin, Od odontoblasts, $P$ periodontal ligament, $B$ bone, $C$ cementum. $B a r s(\mathbf{a}, \mathbf{c}, \mathbf{e}, \mathbf{g}) 500 \mu \mathrm{m},(\mathbf{b}, \mathbf{d}, \mathbf{f}, \mathbf{h}) 50 \mu \mathrm{m}$ 
HE Staining IHC of DSP-NH $\mathrm{N}_{2}$ IHC of DSP-COOH IHC of OPN
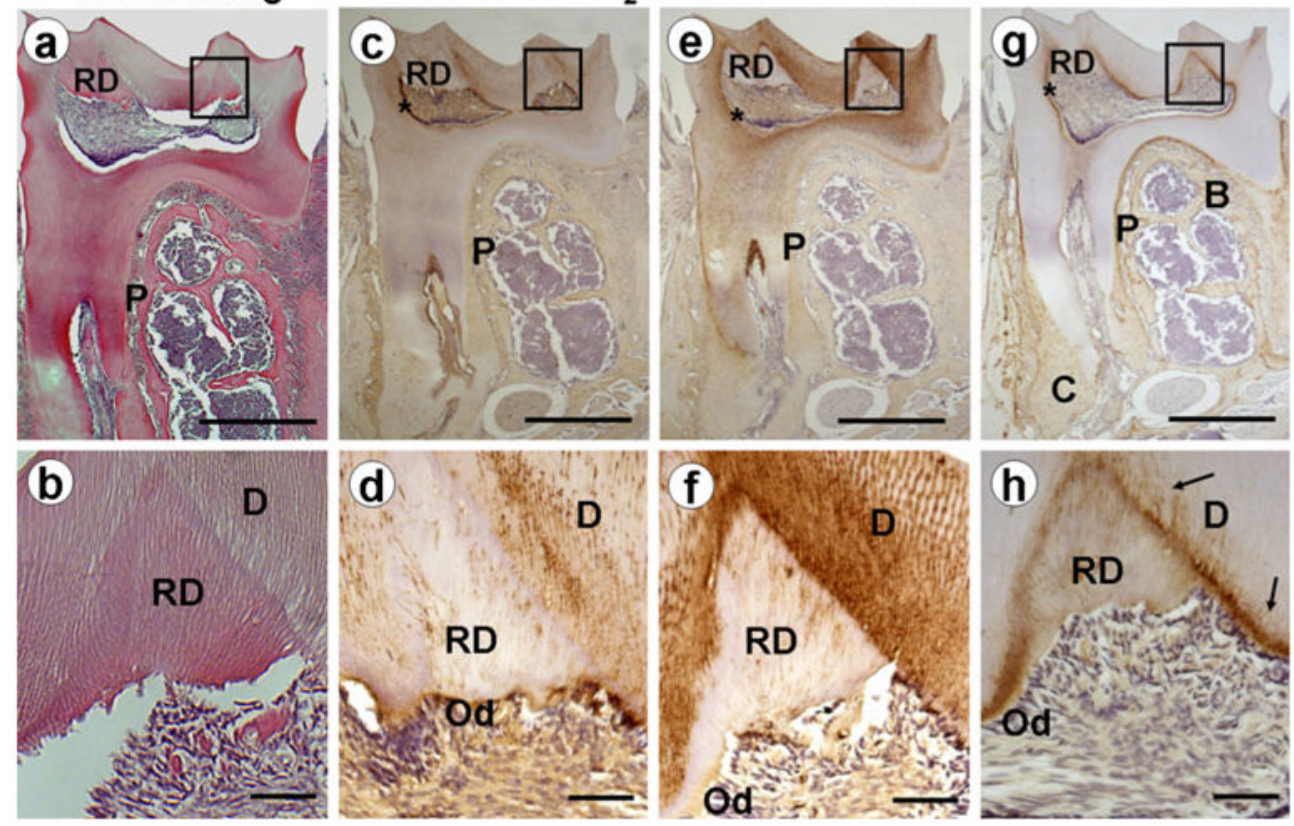

Fig. 5.

$\mathrm{HE}$ staining and immunolocalization of DSP $\mathrm{NH}_{2}$-terminal, $\mathrm{COOH}$-terminal fragments and OPN in mouse molars at M7.5. a, b HE staining showed constituents of molar. c, d AntiDSP-NH $\mathrm{N}_{2}$ antibody stained intensely in predentin (*) and odontoblasts but weakly in RD. e, f Anti-DSP-COOH antibody showed much stronger reactions in mineralized dentin but weak in RD. $\mathbf{g}, \mathbf{h}$ In RD, the immunostaining for OPN was significantly higher than DSP. OPN was intense in RD as well as predentin (*), bone, periodontal ligament and cementum. Some dentinal tubules extending through RD and predentin to dentin stained with OPN (arrows). b, d, f, h Higher magnification of the rectangles in (a, c, e, $\mathbf{g}) . D$ dentin, Od odontoblasts, $P$ periodontal ligament, $B$ bone, $C$ cementum, $R D$ reactionary dentin. Bars (a, $\mathbf{c}, \mathbf{e}, \mathbf{g}) 500 \mu \mathrm{m},(\mathbf{b}, \mathbf{d}, \mathbf{f}, \mathbf{h}) 50 \mu \mathrm{m}$ 